\title{
The effect of a high protein diet on enhanced satiety and weight loss in over weight men and women
}

\author{
N. G. Maloney ${ }^{1}$, S. Stephen ${ }^{1}$, C. L. Fyfe ${ }^{1}$, D. Bremner ${ }^{1}$, G. Horgan ${ }^{2}$ and A. M. Johnstone ${ }^{1}$ \\ ${ }^{1}$ Rowett Research Institute, Bucksburn, Aberdeen, AB21 9SB and ${ }^{2}$ Biomathematics and Statistics Scotland, Rowett \\ Research Institute, Bucksburn, Aberdeen, AB21 9SB
}

High protein (HP) diets are popular for weight loss (WL), but there is limited data on efficacy in free-living studies ${ }^{(1)}$. Laboratory studies indicate that satiety is affected by a number of factors such as palatability, food mass, energy density and fibre and it has been demonstrated altering the macronutrient composition influences appetite, such that protein is more satiating than carbohydrates or fat ${ }^{(2)}$. The current study examines satiety and WL in free-living overweight men and women consuming a commercially available high protein $(30 \%)$, moderate carbohydrate $(40 \%)$ diet, over a four-week period.

We studied forty-two (22 females, 20 males) overweight (mean BMI $33.7 \mathrm{~kg} / \mathrm{m}^{2}$ ), but otherwise healthy adults. All food was provided daily over the 4-week WL period. Volunteers firstly consumed a 7 day maintenance period (1.6 x resting metabolic rate). Volunteers were then provided a commercially available high protein, moderate carbohydrate calorie counted ad libitum diet for a four-week period. To quantify change of eating habits, weighed food diaries were implemented at baseline and week four. Body weight was measured on a weekly basis, while subjective measures of hunger and appetite were assessed using Visual Analogue Scales (VAS) to monitor subjective ratings of hunger and fullness.

Total average weight loss was $4.73 \mathrm{~kg}(p=0.001)$ resulting in a clinical significant $5 \cdot 2 \%$ reduction in body weight. There was a significant reduction in body weight $(p=0.001)$, blood pressure $(p=0.001)$, waist circumference $(p=0 \cdot 001)$ and waist:hip ratio $(p=0 \cdot 001)$. Cholesterol levels had decreased by $18.9 \%$ (4.97 mmol/1 to $4.18 \mathrm{mmol} / 1, p=0.001)$. Glucose levels also declined by $6 \cdot 2 \%(5.45 \mathrm{mmol} / 1$ to $5.13 \mathrm{mmol} / \mathrm{l}, p=0.001)$. Fat intake $\%$ and salt intake were significantly decreased while fibre intake increased significantly $(p=0.001)$. Volunteers were significantly less hungry after the high protein meal compared to a normal protein (NP) test meal $(p=0.007)$. Fullness was significantly more following the HP meal $(p=0.032)$ and onwards after lunch. There were similar ratings of pleasantness, satisfying and palatability assessed 15 minutes after eating.

In conclusion, a protein enriched, calorie counted commercial meals led to a significant weight loss in the short-term, while also having a significant improvements in body composition, blood pressure and bio-markers of health.

1. Skov AR, Toubro S, Rønn B et al. (1999) International Journal of Obesity and Related Metabolic Disorders 23, 528-36

2. Long SJ, Jeffcoat AR, Millward DJ (2000) Appetite 35, 79-88. 